\title{
Proceso inquisitorial de Miguel Rubin de Celis, oficial de la guarnición de Melilla (1770)
}

Carlos Posac Mon

Historiador

En la sección de Inquisición del Archivo Histórico Nacional de Madrid se conservan bastantes expedientes, fechados mayoritariamente en la segunda mitad del siglo XVIII, que atañen a personas residentes en las plazas fuertes que la Corona de España poseía en la costa septentrional de Africa, es decir, enumerándolas de este a oeste: Orán, los llamados Presidios Menores (Melilla, islote de Alhucemas y Peñón de Vélez de la Gomera) y Ceuta. La primera sería abandonada antes de que concluyera la citada centuria, en 1792, como consecuencia del asolador terremoto que la redujo a ruinas en el año precedente. Estaba situada en el litoral de la Regencia de Argel, en tanto que las otras cuatro posesiones tenían a Marruecos como país fronterizo.

Excluyendo una exigua minoría de civiles, los moradores de esas fortalezas pertenecían de manera directa 0 indirecta a la esfera castrense. Unos estaban encuadrados en unidades del Ejército o de la Marina Real. Otros eran presidiarios condenados por la Justicia a cumplir sus sentencias en tierra africana, donde se integraban en unas brigadas paramilitares que servian como fuerzas auxiliares de las guarniciones locales.

Durante el reinado de Carlos III, en el que se enmarca el episodio que voy a narrar, las condiciones de vida en las plazas fuertes del Norte 
de Africa, habían mejorado notablemente respecto a tiempos precedentes en los que, con lamentable frecuencia habían atravesado situaciones catastróficas (1). Sin embargo, todavía resultaba difícil adaptarse a la claustrofobia que originaba la permanencia en un recinto herméticamente cerrado por una línea de murallas. Incapaces de soportar ese ambiente agobiante algunos soldados optaban por la deserción y los presidiarios por la fuga.

Siendo casi imposible escoger el mar como vía de escapatoria, no quedaba otra solución que pasarse al campo de los infieles, cayendo tarde o temprano en manos de éstos, con riesgo de perder la vida o, en el mejor de los casos, los fugitivos se convertían en esclavos de sus captores. Había, no obstante, una solución extrema, convertirse al Islam. Quienes renegaban se convertían automáticamente en vasallos del Sultán, con todos los derechos y deberes que comportaba esta condición. Muchos de los que abjuraban contraían matrimonio con una mujer del país, tenían descendencia y acababan echando firmes raíces en su nueva Patria. Otros, por el contrario, vivían angustiados por los remordimientos y la añoranza y a la primera oportunidad retornaban a alguno de los baluartes africanos de la monarquía española, con la esperanza de que la pena capital, con la que las Leyes sancionaban el delito que habían cometido, fuera conmutada por un castigo menos atroz, lo que solía ocurrir, salvo en los casos en que concurrieran circunstancias agravantes durante la huida.

Ajustadas las cuentas con los Tribunales seculares quedaba todavía a los reos la necesidad de responder ante los eclesiásticos para librarse de la acusación de apostasía. Por lo general éstos dictaban sentencias absolutorias o muy benévolas. Son precisamente tales acusaciones las que tipifican la mayor parte de los expedientes inquisitoriales a que hice referencia al iniciar mi comunicación. En menor proporción éstos tienen su origen en denuncias de delitos de hechicería, blasfemias, bigamia, sodomía o de difusión de proposiciones contrarias a la doctrina católica. Dentro de esta última incriminación figura un proceso que va a ser objeto exclusivo de mi atención. Justifica mi interés la circunstancia de que el reo implicado en él era un personaje que, andando los años, iba a desempeñar un papel relevante en la Historia de España aunque en el tiempo en que se ventilaba su pleito ante el Tribunal de la Inquisición era simplemente un Subteniente de Artillería de la guarnición de Melilla (2).

Se llamaba Miguel Rubín de Celis y antes de ocuparme de sus 
andanzas durante el tiempo que permaneció en esa plaza africana parece oportuno presentar una reseña de su biografía para tener un conocimiento previo de la personalidad del protagonista de mi relato.

\section{SEMBLANZA BIOGRAFICA DE RUBIN DE CELIB}

Miguel Froilán Rubín de Celis era vástago de una familia asturiana de ilustre abolengo, lo que le valdría obtener el título de Caballero del Hábito de Santiago. Había nacido el 17 de octubre de 1746 en el barrio de Santiuste de la parroquia de Pendueles, en el concejo de Llanes. Dotado de gran inteligencia mostró desde muy joven un interés muy marcado por las inquietudes sociales que conmovían a las élites culturales del siglo de las luces. Aprendió varios idiomas y adquirió vastos conocimientos en el campo de las técnicas industriales y en el de la Mineralogía.

Ingresó en el Ejército con el grado de Subteniente de Artillería. Compaginaba el servicio de las armas con el estudio de los sistemas de producción puestos en práctica en las empresas dedicadas a la fabricación de materiales bélicos. Las altas esferas castrenses tuvieron noticia de la valía de sus trabajos, por lo que le confiaron la comisión de recorrer diversas naciones europeas, visitando sus fábricas de armamento con el fin de conocer sus instalaciones y sus métodos laborales.

De vuelta a España, a fines de 1769 estuvo por breve tiempo incorporado a la guarnición de Málaga. Durante su permanencia en esta ciudad frecuentó la tertulia que presidía la condesa de la Puebla del Marqués y, posiblemente, también la que se reunía en casa del abogado Luis de Peñaranda y Haro, tachado por sus conciudadanos de librepensador o la que tenía por sede el domicilio del comerciante inglés Guillermo Leer, señalado por la rumorología local como francmasón y protestante. Imitando el ejemplo de Francia, la buena sociedad española consideraba de buen tono mantener estas tertulias en las que se hablaba de todo lo humano y lo divino.

En la secuencia biográfica de las andanzas de Rubín de Celis hay un capítulo del que hasta ahora no se tenía ninguna noticia y que me propongo ahora sacar a la luz, aportando datos inéditos. Es el que cubre la etapa iniciada a comienzos de 1770, cuando va destinado a la guarnición de Melilla, hasta finales de 1779 . De momento la paso por alto, para ocuparme de ella más adelante.

En los primeros días de diciembre de 1779 Rubín de Celis, que 
hacía varios años había dejado la Artillería para pasar a servir en la Marina Real, iba a bordo de un navío de la escuadra mandada por Miguel Gastón que, en visita de cortesía, hizo escala en la base naval francesa de Brest. Conociendo su experiencia en materia armamentística, el Almirantazgo le encomendó que adquiriese allí un lote de cañones para la flota de guerra nacional y los correos marítimos que hacían la carrera de América. Además, debía obtener informes acerca de nuevos métodos de fundición de metales utilizados en diversas fábricas de armas del país vecino.

Cumplió con toda precisión y puntualidad tales encargos, puntualidad que no tuvo el Erario para abonarle los gastos y gratificaciones presupuestados para la misión que le confiaron. Pasados varios años, en una carta escrita en Cartagena el 14 de julio de 1787, reclamaba a la Hacienda las cantidades que todavía se le adeudaban.

En 1782 pasó al continente americano con un destino en el Virreinato del Río de la Plata, gobernado a la sazón por Juan de Vertiz, quien, informado de sus amplios conocimientos en el campo de la Mineralogía, le encargó que explorara diversas regiones en busca de posibles yacimientos de hierro susceptibles de explotación. El 28 de septiembre de aquel mismo año emprendió viaje desde Montevideo para cumplir la misión encomendada, dándolo por terminado al llegar a Santiago del Estero el 2 de marzo de 1783. Pocas semanas después, estando en la ciudad de Salta, remitió al Virrey un minucioso Diario, en el que recogía los informes solicitados.

Mientras realizaba una nueva prospección minera en la comarca de Potosí, famosa por sus yacimientos de plata, le llegó una Real Orden, por la que se le mandaba retornar a la Península. Cumpliendo este mandato, en el otoño de 1785 embarcaba en un navío que se disponía a zarpar con rumbo a España.

Al reintegrarse a la metrópoli dejó la Marina y se estableció en Cádiz con el propósito de dedicarse a las actividades mercantiles. Poco después y por razones no bien aclaradas G3), se marchó al extranjero casi en calidad de exiliado, fijando su residencia en la ciudad francesa de Bayona, próxima a la frontera española. En el año 1789 le sorprendería allí el estallido de la Revolución Francesa.

Aquella violenta convulsión social, que trastocaría de forma traumática el curso de la Historia, fue acogida con desbordado entusiasmo 
por Rubín de Celis, cuya pluma se puso de inmediato al servicio del nuevo orden político implantado en Francia, redactando sucesivas proclamas y manifiestos en los que, al tiempo de ensalzar el ideario proclamado por la Revolución, incitaba a sus compatriotas a tomar partido por él. Algunos de sus inflamados panfletos pasaron clandestinamente a España, burlando la celosa vigilancia de las autoridades fronterizas, alertadas desde la Corte de Madrid para que no permitieran bajo ningún concepto la difusión de propaganda de matiz subversivo.

La incansable actividad del antiguo Oficial de Marina en la redacción de soflamas revolucionarias ha sido puesta de relieve por el historiador Villas Tinoco quien dice: "quizás el personaje más interesante de cuantos españoles prestaron su colaboración a la publicística francesa, fuese Miguel Rubín de Celis (4)". De su prolífica producción cabe destacar un Discurso sobre los principios de una Constitución libre (5). En su versión francesa fue publicado a expensas de la Sociedad de Amigos de la Libertad y de la Igualdad de Bayona, con fecha del primer año de la República. Se trata de un folleto que analiza el contenido de la Constitución francesa de 1791. Su texto español ha sido reproducido por Antonio Elorza, uno de los historiadores que han prestado mayor atención a la figura de nuestro protagonista (6).

La total identificación de Rubín de Celis con los principios revolucionarios queda reflejada en el hecho de que cuando el 26 de agosto de 1792 se celebraba en Bayona una asamblea para elegir a los representantes locales en la futura Convención Nacional, se presentó en la reunión pretendiendo intervenir en la votación, a título de ciudadano, pese a que su calidad de extranjero no le concedía que ejercitara ese derecho.

Los excesos revolucionarios que desembocarían en el Terror y, sobre todo, la ejecución de Luis XVI desencadenaron la violenta reacción de las principales potencias europeas, incluyendo a España, que se tradujo en una coalición internacional dispuesta a aplastar con las armas a la hidra revolucionaria.

La declaración de guerra a los regicidas galos fue respaldada de forma casi unánime por el pueblo español y adquirió los visos de Cruzada. Como era de esperar, aquella exaltación patriótica también se puso de manifiesto en las plazas norteafricanas del Reino y de una de ellas, Ceuta, partiría una unidad militar, el Regimiento Fijo, para incorporarse a las 
fuerzas que se concentraban a lo largo de la frontera pirenaica dispuestas a entrar en combate contra las hordas regicidas (7).

Colaborando con el Estado Mayor de los soldados de la Convención, el puñado de españoles dispuestos a servir los intereses de la Revolución, entre los que se contaba Rubín de Celis, trataba de reclutar adeptos, enviando emisarios secretos al otro lado de la raya fronteriza con la peligrosa misión de fomentar la deserción de sus compatriotas.

Con muchas dificultades se pudo reunir en Bayona un contingente de doscientos voluntarios, con los que se formó una fuerza bautizada como Legión de Migueletes, dándole como acuartelamiento un antiguo convento, que en tiempos prerrevolucionarios pertenecía a las llamadas Dames de la Foi. Se confió su mando, con el grado de Coronel, a Primo Feliciano Martínez de Ballesteros. El papel de Comisario político (si se me permite usar este título puesto en boga por la Revolución Rusa) correspondió a Rubín de Celis, encargado de adoctrinar a los migueletes en los principios revolucionarios.

Comentando este episodio, opinaba Menéndez Pelayo que "el ex-Oficial de Marina Rubín de Celis era hombre instruido pero fanatizado por las ideas humanitarias y filosóficas de la época". Don Marcelino que, como es bien sabido, no sentía la más mínima simpatía por la Revolución francesa y sus partidarios, subrayaba, con evidente ironía, la palabra humanitarias. Seguía contando: "daba conferencias a los desertores y les explicaba el catecismo de los derechos del hombre".

A continuación se ocupaba del casi ridículo fin que tuvo la flamante Legión de Migueletes, sin haber tenido ocasión de entrar en fuego. Algunos de sus miembros mantuvieron una sangrienta reyerta con soldados del Séptimo Cuerpo de Voluntarios de Burdeos y para evitar represalias los implicados en el enfrentamiento y la mayor parte de sus compañeros optaron por pasar la frontera y presentarse a las autoridades españolas solicitando acogerse al indulto que se había dictado en favor de los desertores (8).

Tras una etapa de dudas y vacilaciones, justificadas por la esperanza de que una política de distensión ayudaría a salvaguardar la vida de Luis XVI, la ejecución del monarca el 21 de enero de 1793 precipitaría los acontecimientos. Señalando que este regicidio evidenciaba la impiedad y la anarquía en que estaba inmersa Francia, Carlos IV ordenó que sus ejércitos lanzaran una ofensiva general contra los de la Convención. En la 
primera fase de la campaña, las tropas españolas obtuvieron excelentes resultados para ser, después, rotundamente derrotadas por las enemigas. Visto el mal cariz de la situación la Corte de Madrid se vio obligada a concertar una paz humillante, firmada en Basilea el 22 de julio de 1795. Estimando que el artífice de este Acuerdo había sido su valido, Manuel Godoy, el soberano le concedió el pomposo título de Príncipe de la Paz.

Los excesos de las turbas indisciplinadas; las disensiones surgidas en el seno de las facciones revolucionarias, violentamente saldadas en el patíbulo, en el que acabaron muchos de los paladines de las luchas por la Libertad; la crueldad de las condenas, fueron factores negativos que acabaron disipando las firmes convicciones progresistas defendidas por Rubín de Celis a lo largo de su vida, una vida que, en los tiempos inseguros que corrían en Francia, bien podía terminar en el filo de la guillotina. Su sentimiento de frustración queda reflejado en el juicio que hizo de él el historiador Muriel, que recojo a continuación, casi con el valor de un epitafio:

Rubin de Celis fue hombre de ilustre nacimiento. Por su afecto a la reforma se huyó de España y fijó residencia en Bayona. Su manía revolucionaria, conocida en Madrid, hizo que se le privase de una de las Cruces de las Órdenes Militares con que estaba condecorado. Se refiere que al ver de cerca los obstáculos que se oponian en Francia al triunfo de la libertad, cual se la habia imaginado $y$ afligido por los errores y extravios que impedían su sólido establecimiento dijo. 'Nunca habría yo creido que la Diosa Libertad sacase la cabeza por lugar tan impuro'. Murió en Bayona (9).

Tras esta semblanza biográfica de nuestro personaje retrocedo cronológicamente para situarme en el momento en que embarca en Málaga para incorporarse a la guarnición de Melilla.

UN VTAJE MARITIMO

Se inicia mi relato el 1 de febrero de 1770 a bordo del navío Rosario que, al mando del patrón Fernando Sotelo, había zarpado de Málaga y surcaba el mar de Alborán con destino a Melilla, cumpliendo un servi- 
cio de enlace entre estas dos ciudades, análogo al que hoy sirven excelentes transbordadores. Viajaban en él varios militares y, probablemente algunos civiles, incluyendo mujeres y niños. La travesía debía hacerse en buenas condiciones meteorológicas, circunstancia propicia para que los pasajeros se entretuvieran en animadas conversaciones.

En la cámara principal del barco, Sotelo había reunido una tertulia, en la que llevaban la voz cantante dos jóvenes Oficiales, el Subteniente de Artillería Rubín de Celis y otro Oficial de la misma graduación, Diego Tapia, que pertenecía al Regimiento de Infantería de la Corona y pasaba a Africa en cumplimiento de una orden de destierro. El tema de conversación no era nada banal y giraba en torno a la denominada virtud magnética, cuyos efectos evidentes recalcaba Tapia, apoyándose en opiniones emitidas por san Agustín y santo Tomás, tomando como fuente las reflexiones de Aristóteles.

Rubín de Celis negaba rotundamente que todo lo grave y lo leve se inclinara indefectiblemente hacia su centro, tal como postulaban esos dos santos varones y su maestro griego, con razonamientos que no tenían ningún fundamento científico. Era cierto que existía una tendencia a unirse en todos los cuerpos pero ello se debía a un fenómeno de atracción, tal como había demostrado con toda claridad el famoso físico inglés Isaac Newton. Añadía provocando, sin duda, el escándalo de todo el auditorio, que en materias de Filosofía los dos Santos citados merecían ser calificados de bestias y sus escritos estaban plagados de errores propios de personas ignorantes.

En la controversia ambos interlocutores derrocharon erudición, entremezclando en sus argumentos abundantes citas en latín, lo que produjo mucha impresión en doña Camila Muñoz, una de las pasajeras presentes en la reunión, que debió quedar admirada por los profundos conocimientos humanísticos de ambos militares. Admiración que se acrecentó cuando horas más tarde los vio conversando en la cubierta y pudo comprobar que utilizaban en la charla el latín y el francés, con toda fluidez.

\section{RUBIN DE GEISIS BN MTSLILLA}

Cuando Rubín de Celis desembarcó en Melilla para incorporarse a su guarnición, la situación militar de la plaza era de relativa tranquilidad. Desde la firma del Tratado de Paz y Comercio concertado entre España y Marruecos en mayo de 1767, gracias a las hábiles gestiones diplo- 
máticas desplegadas por el famoso marino Jorge Juan, las relaciones entre los dos países signatarios eran satisfactorias e incluso cordiales, al menos a nivel oficial, propiciando fructíferos contratos comerciales (10). Sin embargo, los díscolos súbditos del Sultán que habitaban en las zonas inmediatas a Melilla, desobedecían sin recato las órdenes de su soberano y, aunque de forma esporádica y a escala mínima, no cejaban en sus actos de hostigamiento contra esta plaza y los otros dos Presidios Menores. Esta actitud hostil obligaba a que sus defensores nunca bajaran la guardia.

En aquel tiempo la guarnición de Melilla contaba con unas unidades de infantería propias de la plaza, que se nombraban fijas y estaban integradas principalmente por los naturales de ella, más de una fuerza de variable consideración, a tenor de las circunstancias bélicas, que componían a la sazón los Regimientos de España y de Nápoles. En este último, tanto los cuadros de mando, como la tropa eran en su mayoría oriundos de la península Apenina. Completaban la dotación destacamentos de artillería, ingenieros y marinos. Con carácter paramilitar existían en la ciudad varias brigadas de presidiarios.

Por su condición de baluarte que estaba virtualmente en perenne estado de guerra, Melilla tenía como autoridad suprema, con amplísimos poderes, un Gobernador Militar. Desde el 22 de mayo de 1767 ocupaba este cargo el Coronel de Infantería Luis Fernández de Saavedra. Era natural de Ceuta y tenía bastante experiencia en la tarea por haber ejercido la misma titularidad en el islote de Alhucemas durante casi seis años (11). La muerte que le sobrevino el 27 de enero de 1772 pondría término a su mando (12).

La imposibilidad de salir al campo exterior para practicar la caza o hacer excursiones obligaba a los militares de Melilla a distraer sus ocios con frecuentes reuniones en las casas particulares. También el Gobernador era amigo de esta clase de actos sociales y los organizaba en su residencia, invitando a ellos a los mandos castrenses y a los principales representantes del estamento civil.

Parece ser que Rubín de Celis aceptó con gusto aquel tipo de distracción, convirtiéndose en asiduo participante en algunas de las tertulias. Consta, por ejemplo, su presencia en la que se reunía en casa de Andrés Amat Tortosa, un Capitán de Ingenieros granadino que durante un par de años residió en Melilla cumpliendo el encargo de mejorar sus fortifi- 
caciones y pasó poco después a Orán con la misma tarea. También acudía a la presidida por el Capitán Antonio Manso, jefe de una Compañia Fija y que solía invitar a su mesa a sus contertulios. Estaba presente o, al menos, se hablaba mucho de él en la que tenía por anfitriona a doña Clara Morales, una dama de la buena sociedad local. Y para no extenderme demasiado diré, por último, que iba con asiduidad a las reuniones que había en casa del Gobernador.

En todas las ocasiones Rubín de Celis era uno de los encargados de llevar la voz cantante y, casi siempre, fustigando con cáustica ironía los dogmas más sagrados de la religión cristiana y a sus ministros. Su dialéctica parecía encontrar sus fuentes de inspiración en el ideario que al otro lado de los Pirineos difundían Voltaire y los más conspicuos enciclopedistas.

$\mathrm{Su}$ manera de actuar recuerda la del modelo de oficial propuesto por Cadalso en su opúsculo El buen militar a la violeta, considerado como un apéndice a su famosa sátira Los eruditos a la violeta (13). Según define el autor, el arquetipo de Oficial ideal debe poseer, entre otras condiciones, una decidida tendencia a la irreligiosidad. Como el lenguaje humorístico suele caricaturizar una realidad, pero no inventarla, debemos suponer que entre los militares españoles coetáneos de Cadalso y de Rubín de Celis no faltaban los que, bien por convicción, bien por esnobismo, se mostraban proclives al agnosticismo.

En una de las habituales reuniones convocadas por el Gobernador, en las que solían organizarse partidas de naipes, salió a conversación el tema de la piedra filosofal. Como es bien conocido, desde los tiempos medievales los alquimistas habían multiplicado los experimentos en sus rudimentarios laboratorios con la esperanza de descubrir esa piedra imaginaria, a la que se atribuía la propiedad de transmutar en oro cualquier mineral que se pusiera en contacto con ella.

En opinión del Gobernador, los Capuchinos ya habían encontrado al fin tan maravilloso producto en sus refectorios. Su Excelencia, sin duda, hablaba en sentido metafórico, poniendo de relieve que estos religiosos alcanzaron la fórmula de una aúrea existencia, gracias a su vida ejemplar. (Recordemos que los frailes de la Orden Capuchina tenían encomendada la misión de atender las necesidades espirituales de la grey melillense). Con la misma intención de ensalzar a tan santos varones, uno de los Oficiales presentes, Lucas Galeti, Capitán del Regimiento de Nápoles dijo 
que su verdadero descubrimiento había sido una fórmula eficaz para garantizar la salvación de sus almas, merced a las disciplinas adecuadas y a los ayunos. Le contradijo Rubín de Celis, asegurando que hasta el presente nadie conocía un método infalible para alcanzar tal salvación. Un tanto molesto, Galeti le replicó que esas palabras le sonaban a herejía.

En otra ocasión el Gobernador se reunió con la Oficialidad de la plaza en una sala situada en la planta baja de su residencia. Estaban presentes, entre otros, Miguel Rubín de Celis, Lucas Caleti, Juan Ignacio Alcázar, Capitán del Regimiento de España y Cayetano Turati, Teniente de Nápoles. Siguiendo su inveterada costumbre el primero puso de manifiesto su ideología racionalista. Dijo que ningún hombre de ciencia -y él se debía considerar como tal- se dejaba convencer por las doctrinas de ninguna religión.

Rubín de Celis se jactaba de tener algunos libros prohibidos. Prestó uno de ellos, escrito en francés por Madame Ninon de Andou, a Pedro Mercadillo, un Teniente de Ingenieros que tras su lectura consideró que estaba plagado de proposiciones malsonantes. A cambio de otro libro, cuyo título no consta, cedió a este Oficial un volumen impreso en el año 1611, cuyo autor se llamaba Melchor Junio Vitembergensis. En sus páginas se contenían acerbas críticas contra el celibato, refutando argumentos expuestos en las Sagradas Escrituras, así como en las Epístolas de San Pablo.

Es de suponer que las peroratas de Rubín de Celis eran objeto de numerosos comentarios en la sociedad melillense. Unos estarían concordes con su manera de pensar aunque, probablemente, parte de ellos no se atreverían a manifestarlo por temor a posibles represalias de la Inquisición, que los acusaría de cómplices de un hereje notorio. Otros considerarían que no merecía dar excesiva importancia a la conducta, un tanto inconsciente, del militar asturiano que, tal vez, sólo pretendía impresionar a la gente sencilla presentándose como paladín de la llamada Ilustración, aquella especie de religión laica — valga el contrasentido- que habían puesto de moda los intelectuales europeos.

Había finalmente un tercer grupo, probablemente mayoritario, que contemplaba con profundo disgusto la actitud irreverente de Rubín de Celis y estaba dispuesto a poner término a lo que, en un principio, bien pudo calificarse como una extravagancia pero que, por su pertinacia, significaba una intolerable ofensa al sentimiento religioso de la gente y un peligro para el orden social. Era necesario escarmentar al lenguaraz Oficial y el 
instrumento legal más adecuado para ello era el Tribunal de la Santa Inquisición. Esta institución ya no actuaba a aquellas alturas con la severidad que lo había hecho temible en épocas pretéritas pero todavía conservaba casi intactas sus prerrogativas y seguía luchando con eficacia en la represión de los delitos contra la religión católica.

\section{PROOFBO INQUISTTORIAI CONTRA RUBIN DE CELIS}

El 27 de noviembre de 1770 el Tribunal de la Santa Inquisición de Granada recibió una comunicación fechada en Melilla el 13 del mismo mes y que firmaba Francisco Turrillo, Vicario interno de la plaza. Venía con ella una denuncia de Manuel Ahuir, incriminando al Subteniente de Artillería Miguel Rubín de Celis de propalar públicamente proposiciones contrarias a la religión. Puesto que no existía en la ciudad un Tribunal del Santo Oficio encargado de desterrar todo género de errores, el denunciante recababa la colaboración del Vicario para que en su calidad de Juez eclesiástico promoviera el oportuno expediente judicial, evitando incurrir en las censuras de las autoridades inquisitoriales.

Atendiendo a aquella denuncia que les llegaba de la fortaleza norteafricana, los inquisidores granadinos ordenaron la incoación de un proceso, encomendando a Turrillo que procediera al interrogatorio de cuantos testigos pudieran aportar datos de interés. Tomando como fuente informativa las declaraciones que prestaron éstos, podemos conocer las circunstancias que condujeron al acusado ante el Tribunal de la Inquisición, colocándolo en una comprometida situación que, por otra parte, era de prever, pues desde su llegada a Melilla, con su incontinencia verbal, había ido acumulando méritos sobrados para caer, tarde o temprano, en las redes del Santo Oficio.

Todos los testigos manifestaron que los hechos denunciados tuvieron por escenario la residencia del Gobernador pero, en cambio, no se pusieron de acuerdo al señalar la fecha. Resulta curioso que incluso el responsable de la delación tuviera dudas al respecto, diciendo "creo que fue a finales de septiembre". Uno de los declarantes no podía recordar si el día de autos cayó en la fiesta de San Miguel (29 de septiembre) o en la de San Carlos (4 de noviembre). Es bastante extraño que dado el poco tiempo transcurrido desde la comisión del delito, hasta el 20 de diciembre de aquel mismo año 1770 , en que se efectuó la prueba testifical, se produjeran tales 
síntomas de amnesia. Pienso que, en realidad, la denuncia no correspondía a una ocasión única, sino que cabría considerarla como acumulativa, sumando en ella diversas intervenciones escandalosas del presunto reo.

Concediendo mayor credibilidad a quienes situaban la acción delatada en la jornada del 20 de septiembre, digamos que ese día el Gobernador ofreció una recepción en su residencia para celebrar su onomástica. Debió concurrir a ella el "tout Melilla". Entre los invitados del estamento civil destacaban Manuel Alonso, veedor interino de la Real Hacienda, Juan de Arriaga, factor encargado de Abastos y Manuel Ahuir, médico titular de la plaza, a quien ya conocemos. Tenía cuarenta años de edad y había nacido en el pueblo valenciano de Algemesí, situado en las proximidades de la desembocadura del Júcar.

En la nutrida representación militar figuraban los Capitanes Antonio Manso, Lucas Galeti y Juan Ignacio Alcázar, los Tenientes Pedro Mercadillo y Cayetano Turati, todos citados anteriormente y, con ellos, el Capitán Juan Antonio Pérez, los Tenientes Antonio Bonet (o Benis), Ignacio Muñoz y Miguel Ruiz, los tres Oficiales del Regimiento de infantería de España, el Teniente Felipe Gaudino, del de Nápoles y, cómo no, el Subteniente de Artillería Miguel Rubín de Celis, que también celebraba el día de su Santo.

Este, siguiendo su inveterada costumbre intervenía en los corros que se formaban, arremetiendo contra los principios religiosos, poniendo tanto ardor en sus palabras que uno de los presentes comentó que más que hablar vociferaba. Se le oyó comentar que la religión no era sino un acto arbitrario de algunas gentes, una invención voluntaria establecida por un conjunto de hombres. El infierno no existía, era pura imaginación. Cuando ponía en tela de juicio el misterio de la Encarnación intervino el Gobernador reconviniéndole. "Señor mío - le dijo- Vuestra Merced y yo somos unos ignorantes para tratar esas materias por lo que no vuelva Vuestra Merced a hablar de ellas en mi casa".

No hizo mucho caso de la reprimenda de su superior porque poco después se enzarzaba en una acalorada discusión con el doctor Ahuir y el Capitán Galeti. Eran testigos pasivos de la controversia el veedor Alonso y el factor Arriaga que optaron por retirarse discretamente para no verse comprometidos en la trifulca que parecía acercarse. Cuando el primero se alejaba oyó decir con voz estentórea al Oficial de Artillería que estaba segu- 
ro de salvar su alma por muchos pecados que tuviera porque tenía fe absoluta en la bondad de Dios. Afortunadamente no se produjo ningún acto de violencia pero la ocasión sirvió de pretexto al médico para denunciar a su antagonista ante el Tribunal de la Inquisición de Granada.

\section{OTRO VIAJB MARTMIMO DE RUBIN DE CEIIS}

Mientras acumulaba testimonios para esclarecer las culpas que se imputaban a Rubín de Celis, el Tribunal de Granada tuvo noticia de que no era la primera vez que el reo había sido denunciado por sostener opiniones heréticas. Según informes que le remitió el Santo Oficio de Valencia, tenía éste en curso un proceso contra él, abierto tras una delación voluntaria presentada el 5 de octubre de 1769 por un tal Pedro Puig, lapidario de profesión, de 43 años de edad, natural de Barcelona y con residencia en la ciudad del Turia.

Los hechos denunciados habían ocurrido durante una travesía marítima. Rememorando lo sucedido durante el trayecto del navío Rosario a comienzos de febrero de 1770 , podríamos ironizar señalando que los viajes por mar estimulaban el espíritu crítico y la locuacidad irreverente de nuestro protagonista. En esta ocasión iba a bordo de un barco francés que, al mando del Capitán Joseph Venel, había zarpado del puerto de Marsella el 8 de septiembre de 1768, con destino a Valencia, llevando ocho o nueve pasajeros. El denunciante no podía recordar su número exacto.

Uno de los viajeros era Rubín de Celis que retornaba de un viaje por Italia. Pronto entabló conversación con algunos de sus compañeros de ruta: un matrimonio ya maduro formado por el genovés Francisco Meloño y la española María Martínez, a los que acompañaba un hijo veinteañero; un joven francés, Antoine Dupin, nacido en Grenoble, que era portador de una carta de recomendación para el Capitán General de Valencia, con cuyo apoyo confiaba obtener un empleo de escribiente en una empresa comercial dirigida por su compatriota monsieur Galbin y también con Pedro Puig, que acabaría delatándolo a la Inquisición.

Siguiendo su costumbre inveterada Rubín de Celis escogía como tema preferente de conversación temas teológicos en los que volcaba críticas demoledoras que no voy a pormenorizar porque su contenido era análogo al que ya hemos expuesto anteriormente. Por escrúpulos de conciencia el lapidario catalán, transcurrido casi un año, las puso en conoci- 
miento de los inquisidores valencianos. Estos prolongaron las pesquisas hasta bien entrado 1773, dando cuenta de sus resultados al Tribunal de Granada. Para no ser prolijo y dado que no aportan datos de interés, pongo final a este episodio no sin antes referir las desagradables consecuencias que tuvo para la familia Meloño verse implicada indirectamente en el proceso promovido contra Rubín de Celis.

La Inquisición de Valencia hizo indagaciones para dar con el paradero del genovés, a fin de obtener su testimonio. Pudo averiguarse que residía en Beniganim, un pueblo valenciano próximo a la ciudad de Játiva, pero también se supo que la que pasaba por su esposa era una pobre viuda que le servía como criada y con la que estaba amancebado. Cuando Meloño le anunció que tenía que ir a Marsella, decidió partir con él, confiando en que se casaría con ella durante la estancia en la ciudad francesa, esperanza que resultó fallida. En cuanto al hijo que los acompañaba en el viaje de retorno, no tenía ningún parentesco con ellos, se llamaba Félix Rosi y se trasladaba a Alicante con el deseo de encontrar trabajo como sirviente de librea. Descubierto el enredo el genovés fue encerrado en la cárcel de la Torre de Serranos, pasando de la condición de testigo a la de acusado.

IRL PROCESO DE RUBIN DE CEIS PABA A LA INQUISICION DE ILERTINA

Rubín de Celis salió de Melilla para un nuevo destino en Cádiz. Posiblemente en este traslado cambió la Artillería por la Marina. No he podido precisar la fecha de su partida por lo que ignoro si tomó parte en la defensa de la plaza durante el sitio que le puso el Sultán Sidi Muhammad ben Abdallah desde el 9 de noviembre de 1774 hasta el 19 de marzo de 1775 .

El cambio de residencia no ponía final a sus problemas con la Inquisición. Su expediente, incluyendo los autos del proceso de Valencia, fue remitido por el Tribunal de Granada al de la ciudad extremeña de Llerena, a cuya jurisdicción pertenecía Cádiz.

Según consta en un documento redactado el 7 de febrero de 1776, el Inquisidor Fiscal de Llerena daba audiencia de cargos a Miguel Rubín de Celis, Teniente de Fragata, de 29 años de edad, acusado de proposiciones contrarias a la religión, preso en las cárceles secretas de la Inquisición. Tras escuchar al reo, el Tribunal decidió reprenderlo gravemente, 
conminándolo a que en lo sucesivo se abstuviera de tratar siempre puntos de religión, con lo que se suspendería la sumaria.

No se conformó el procesado con las advertencias que se le hacían y vista tal contumacia el Consejo votó el 24 del mismo ves que quedase preso en cárceles secretas del Santo Oficio con embargo de bienes, libros y papeles y que siguiera la causa hasta que se dictara sentencia definitiva. Tales disposiciones se cumplieron puntualmente.

Al fin, ratificados los testigos, calificadas en plenario las propuestas hechas por parte del reo y de las defensas que pidió, los inquisidores Alvaro Valcárcel y Joaquín Lacunza, con poder del Ordinario de Badajoz, dictaron sentencia el 27 de noviembre de 1776, condenando al acusado a que presente en la Sala de Tribunal, a puerta cerrada y ante los ministros del Secreto, con hábito de penitente y llevando un sambenito de media aspa, que le quitarían cuando terminara la ceremonia, escucharía los términos de los motivos por los que se le castigaba. Luego tendría que abjurar de vehementi. Cumplidos los requisitos sería absuelto ad cautelam tras los oportunos apercibimientos y reprensiones. Como pena subsidiaria se le desterraba de Madrid y de otros puntos que se señalaban en el veredicto. Por último se le imponían quince días de ejercicios espirituales que debía realizar en su prisión.

Así terminaba tras seis largos años — siete si contamos el de Valencia - el proceso contra Rubín de Celis, un hombre que andando el tiempo se haría famoso entre sus contemporáneos pero con el estigma de traidor a su Patria y a su Rey. Hoy, con la objetividad que proporciona la perspectiva histórica, pienso que merece admiración porque movido por ideales generosos se consagró a la lucha por los derechos del Hombre, teniendo como divisa una hermosa ideología: Libertad, Igualdad, Fraternidad. 
1. De las penalidades, sufridas por los moradores de Melilla ofrece una dramática visión: Jesús F. SALAMANGA ORTEGA, Bosquejo histórico de la población y guarnición de Melilla (1497-1874), Granada 1987.

2. Los documentos que contienen el proceso de Rubín de Celis figuran el la citada sección de Inquisición, en los legajos 3731 (expediente 71) y 3735 (expediente 167). Sobre este personaje también hay datos en la sección de Estado, legajos 2899 y 3918.

3. En una carta fechada el 12 de septiembre de 1792 achacaba su destierro al hecho de haber denunciado en la Corte "el robo más calificado que se le hacía al Rey en la negociación de azogue". El azogue o mercurio estaba monopolizado por el Estado.

4. VILLAS TINOCO, S.: Málaga en tiempos de la Revolución Francesa, Málaga 1979, pág. 214.

5. Un ejemplar de este folleto se conserva en el A. H. N., sección de Estado, legajo 3918.

6. ELORZA, A.: Pan y toros $y$ otros papeles sediciosos de fines del siglo XVIII español, Madrid, 1970.

7. CRIADO, M. y ORTEGA, M. L.: Apuntes para la Historia de Ceuta, Madrid 1925, pág. 405.

8. MENENDEZ Y PELAYO, M.: Estudios y discursos de Crítica Histórica y Literaria, edición de OBRAS COMPLETAS de la Editora Nacional, tomo IV, Madrid 1942, págs. 142-3.

9. MURIEL, A.: Historia de Carlos $I V$, edición de la B.A.E., Madrid 1959, pág. 198.

10. LOURIDO DÍAZ, R.: Marruecos y el mundo exterior en la segunda mitad del siglo $X V I I$, Madrid 1989, págs. 405 y sgs.

11. MORALES, G. de: Datos para la Historia de Melilla, Melilla 1909, págs. 522 y 529.

12. Archivo Diocesano de Málaga, sección histórica, Vicaría de África, Caja 41, libro 6 de Defunciones.

13. Ese opúsculo se publicó en Sevilla en 1790 , varios años después de la muerte de José Cadalso frente a Gibraltar. Posiblemente fue compuesto casi al mismo tiempo que "Los eruditos a la violeta", cuya primera edición es del año 1772. 